\title{
Narrative review of classification and management of solitary pulmonary nodule: the state of art
}

\author{
Alessandro Gonfiotti, Alberto Salvicchi, Luca Voltolini \\ Thoracic Surgery Unit, Careggi University Hospital, Florence, Italy \\ Contributions: (I) Conception and design: G Alessandro, S Alberto; (II) Administrative support: G Alessandro, S Alberto; (III) Provision of study \\ materials or patients: G Alessandro, S Alberto; (IV) Collection and assembly of data: G Alessandro, S Alberto; (V) Data analysis and interpretation: \\ All authors; (VI) Manuscript writing: All authors; (VII) Final approval of manuscript: All authors. \\ Correspondence to: Alberto Salvicchi, MD. Thoracic Surgery Unit, University Hospital Careggi, Largo Brambilla, 1, 50134 Florence, Italy. \\ Email: alberto.salvicchi@libero.it.
}

\begin{abstract}
Objective: Solitary pulmonary nodule (SPN) is defined as a lung lesion less than $30 \mathrm{~mm}$ in diameter. The etiology of SPNs is generally benign, however, they may represent an early malignant process. This article aims to provide an overview of the management of SPN, including clinical and radiological evaluation.

Background: SPN has frequently been encountered during clinical practice and its management poses a challenge for clinicians. Clinical assessment and computed tomography (CT) features are important to establish the correct diagnostic pathway for patients. Evaluation of the pulmonary nodule requires an integrated approach in order to reveal an early malignancy and to prevent health-damaging diagnostic over investigations. Nodule size, volume doubling time (VDT), margin characteristics, location and composition help identify behavior of pulmonary nodules and should guide decision regarding biopsy, positron emission tomography (PET)/CT and/or CT surveillance. Benign conditions should also be considered in the diagnostic evaluation. Quantitative prediction models have been developed in order to estimate the probability of malignancy, and guidelines provide accurate diagnostic algorithms for pulmonary nodule management.
\end{abstract}

Methods: This review was performed by finding the most relevant articles regarding the management and treatment of SPN. We searched the PubMed and MEDLINE platforms including only articles in English, and then an extensive literature review was done.

Conclusions: Current guidelines provided detailed recommendations on the decision-making of the pulmonary nodule. Moreover, several clinical studies have evaluated the effectiveness low-dose computed tomography (LDCT) as a screening method, as early detection of lung cancer could have a higher curative potential. In this review, we discuss the overall management of patients with SPN and we summarize the highlights of the main guidelines in this regard.

Keywords: Pulmonary nodule; sub-solid nodule; ground glass nodule; lung cancer

Received: 21 April 2021; Accepted: 12 August 2021; Published: 30 June 2022.

doi: $10.21037 /$ asj-21-18

View this article at: https://dx.doi.org/10.21037/asj-21-18

\section{Introduction}

Solitary pulmonary nodule (SPN) is an ordinary clinical problem and diagnostic challenge for clinicians. SPN is a single nodule measuring less than $30 \mathrm{~mm}$ and is frequently detected as incidental finding on computed tomography
(CT) performed for other clinic reasons. Currently the identification of pulmonary nodules is growing with the increased utilization of CT and chest X-rays.

Many of the abnormalities detected on radiological scans are often benign but it is important to identify the etiopathogenetic nature of the nodule since it could be a 
malignancy representing early lung cancer. Differentiating the benign and malignant nature of these nodules could be very challenging in the absence of biopsy. The goal to be achieved is to identify as many early malignancies as possible, minimizing over investigation.

Several guidelines for the assessment and management of pulmonary nodules have been developed and include those of the Fleischner Society Guidelines (2017) and American College of Chest Physician (2013).

The focus will be on SPN and the aim of this review is to discuss the management and treatment of pulmonary nodules. We present the following article in accordance with the Narrative Review reporting checklist (available at https://asj.amegroups.com/article/view/10.21037/asj-21$18 / \mathrm{rc})$.

\section{Methods}

This paper was performed by finding articles on PubMed platform by inserting the following keywords in the search field: Pulmonary nodule, sub-solid nodule, ground glass nodule, Lung cancer.

\section{Discussion}

\section{Definition and incidence}

A SPN is defined as a focal rounded or irregular opacity, which may be well-or poorly defined, measuring less than $30 \mathrm{~mm}$ in maximal diameter and is surrounded completely by aerated lung parenchyma (1), and is not associated with lymphadenectomy, atelectasia or pneumonia (2).

A lesion $>30 \mathrm{~mm}$ is classified as pulmonary mass, nota a nodule. Greater than $90 \%$ of lung masses are malignant (3).

With the growing use of high-resolution imaging modalities, the number of SPNs found incidentally is more and more frequent; it is estimated a prevalence varying between $2 \%$ and $24 \%$ (1), and is $17 \%$ to $53 \%$ in those who have undergone lung cancer screening programs (4). The incidence of malignancy in patients with SPN ranges from $10 \%$ to $70 \%(5)$.

Several risk factors have been identified as the cause of pulmonary malignancy such as increasing age, smoking addiction, previous malignancies, chronic obstructive pulmonary disease (COPD), intestitial lung disease and asbestos exposure (6).

Therefore, in the management and assessment of pulmonary nodules it is essential to carry out a careful evaluation of the patients' risk factors and their clinical history. However, the absence of risk factor does not preclude a malignant diagnosis (7).

\section{Causes and etiology}

The etiology of SPNs is generally benign, however the hypothesis of a malignant process should be considered (4) and careful differential diagnosis performed. There are many causes of SPN (Table 1). Benign diagnoses include granulomas, hamartomas, organizing pneumonia, tuberculosis, chondromas, Wegener granulomatosis, rounded atelectasis etc. Malignant etiologies include bronchogenic carcinoma, solitary pulmonary metastasis, lymphoma and carcinoid tumors (8).

Then there are a number of conditions that can mimic the presence of a nodular lesion such as nipple shadow; rib fracture or other bone lesion; vanishing pseudotumor of congestive heart failure; artifact and cutaneous lesion (e.g., wart, mole).

\section{Clinical and radiological evaluation}

Clinical evaluation is fundamental because it helps to distinguish benign from malignant pulmonary nodules through the evaluation of risk factors and radiological features. Usually, patients with SPN are asymptomatic and the onset of symptoms is often related to nodule growth and progression of malignancy (9). The malignant etiology of the SPN is more associated with risk factors such as smoking history, older age, interstitial lung disease, previous cancer, emphysema and asbestos, radon and uranium exposure (10-13).

The radiological features of both benign and malignant pulmonary nodules often overlap but several predictive characteristics have been identified for risk stratification. These include nodule size, volume doubling time (VDT), margin characteristics, calcifications and location. Therefore, an accurate CT characterization is the recommended modality for assessment of SPNs (13).

According to the BTS and Fleischner guidelines, lowdose CT (LDCT) should be performed in the study of the pulmonary nodule, given the possibility of repeated CT examinations during follow-up $(2,14)$. Several studies have shown that the diagnostic accuracy of a LDCT is comparable to that of a standard-dose CT; the sensitivity of LDCT was greater than $92 \%$ for all nodules, and $97.4 \%$ for nodules $\geq 5 \mathrm{~mm}$ (15).

For accurate characterization of small nodules, 
Table 1 Differential diagnosis for SPNs

Solitary pulmonary nodule: differential diagnosis

- Primary lung cancer

- Solitary metastasis

- Pulmonary chondroma

- Pulmonary hamartoma

- Vascular nodule

- Inflammatory nodules

- Traumatic

- Congenital

- Rheumatoid arthritis

- Pulmonary sarcoidosis

- Hematoma

- Intraparenchymal lymph node

SPN, solitary pulmonary nodule.

Table 2 Correlation between nodule size and likelihood of malignancy

\begin{tabular}{lc}
\hline Nodule diameter $(\mathrm{mm})$ & Risk of malignancy \\
\hline$<6$ & $<1 \%$ \\
$6-8$ & $0.5-2 \%$ \\
$8-10$ & $3 \%$ \\
$11-20$ & $33-60 \%$ \\
$>20$ & $64-82 \%$ \\
\hline
\end{tabular}

guidelines recommend performing thin section in all CT scan of the thorax: the Fleischner Society recommends performing contiguous thin sections typically $1 \mathrm{~mm}$, however not higher than $1.5 \mathrm{~mm}$ (14), the British Thoracic Society (BTS) guidelines recommend a slice thickness of no more than $1.25 \mathrm{~mm}$. Thick sections does not allow an accurate evaluation of smaller nodules because it increases volume averaging.

\section{Nodule size}

The likelihood of malignancy is positively correlates with the nodule size. In the literature numerous studies showed that the diameter growth is associated with a higher risk of developing malignancy $(6,8,9,16)$. In nodules smaller than $6 \mathrm{~mm}$ the risk of cancer is estimated around $1 \%$, those that are between 6 and $8 \mathrm{~mm}$ have an average risk of $0.5-2 \%$.
A nodule diameter greater than $8 \mathrm{~mm}$ has a $3 \%$ chance of being malignant (14). The prevalence of malignancy rises to $33-60 \%$ in SPNs which have a diameter of $11-20 \mathrm{~mm}$ and to $64-82 \%$ in nodules larger than $20 \mathrm{~mm}$ (Table 2) (17). SPNs with less than $1 \%$ cancer risk do not require routine follow-up with CT scans (14).

\section{Volume doubling time (VDT)}

VDT is defined as the time required for a growing nodule to double its volume or to increase $26 \%$ in diameter (18). The volume of the nodules is calculated using the equation $4 / 3 \pi r^{3}$. A longer VDT suggests a more benign course, whilst a short VDT is indicative of a more aggressive lesion. According to most studies a VDT below 400 days represents a high likelihood of malignancy (9.9\%), a VDT between 400 and 600 days has a risk of malignancy of $4 \%$ days, whereas a VDT above 600 days is overwhelmingly characteristic of a benign nodule (19). A growth of nodule extremely fast with VDT $<20$ day reflects an infection process (20). Generally malignant pulmonary nodules have a VDT of between 30 and 400 days (21). However, it should be noted that subsolid nodules, ground glass opacity (GGO) (22) and part-solid, can take a longer time to develop into malignant lesions with a VDT of 547-813 days.

\section{Margin characteristics}

Malignant nodules tend to have irregular and spiculated margins, often described as sunburst or corona radiata. Benign nodules have well-defined, smooth and regular margins. A lobulated margin has an intermediate risk of cancer. However, there are benign conditions that have spiculate margins such as focal atelectasia, tuberculoma, massive fibrosis (9).

\section{Calcification}

A pattern of calcification may be present within the SPN and it can help in risk stratification.

A pattern of calcification can be found in both benign and malignant nodules. Typically, a diffuse solid calcification, central, lamellar, or popcorn pattern of calcification are associated with a high likelihood of being benign (9). SPN, as an expression of primary lung tumors, demonstrate calcifications on CT scans up to $6-10 \%$ (23). Malignant nodules often have a pattern characterized by stippled or eccentric calcifications.

\section{Location}

Generally, upper lobe distribution is considered an 
independent risk factor for malignancy with an odds ratio of 1.9 (13). An SPN located in an upper lobe has a 1-5\% higher risk of lung cancer than other locations (24). This could be due to a higher concentration of inhaled carcinogens in the upper lobe (13). Especially, the nodules with the highest rate of malignancy appear to be located in the right upper lobe.

Positron emission tomography (PET) may also be useful in the characterization of pulmonary nodules. PET is a radiological investigation, that allows the evaluation of the disease presence and extent in cancer patients. The combination of PET and CT scanning (PET/TC) measures metabolically active tissue, by increased uptake of a radiolabelled glucose isotope 18-fluorodeoxyglucose (FDG). Usually, malignant lesions present higher glucose metabolism than non-malignant cells and therefore concentrate FDG more avidly than normal tissue. It is possible to measure the metabolic activity of SPN through the standardized uptake value (SUV). The cut off between benign and malignant nodule is in the SUV value 2.5; using SUV > 2.5 to identify malignant SPNs, PET/CT showed sensitivity and specificity at 87-94.2 and $83 \%$ respectively (13).

In addition, clinicians should keep in mind the likelihood of getting false positive (e.g., inflammatory episodes or infection) and false negative (e.g., carcinoma in situ) findings. Also, PET has a lower sensitivity for small lesions $(<8 \mathrm{~mm})$ and therefore the guidelines recommend [Fleischner Society and American College of Chest Physicians (ACCP)] recommend performing PET in conjunction with CT scan for the evaluation of SPNs $>8 \mathrm{~mm}$. The use of PET should be avoided for non-solid nodules and replaced by thin section CT which performs well in these circumstances (25).

\section{Stratification risk model}

The evaluation of pulmonary nodules can be facilitated by the use of multiple quantitative models that have been developed to help the estimation of the pretest probability of malignancy. Several prediction models have been validated using logistic regression; the most commons include the Mayo Clinic (26), Brock University (6), Herder model (27) and Veterans Affair (17). The accuracy of predictive models appears to be similar, but the model to be used should consider the characteristics of the selected population (9). Swensen et al. developed a model (Mayo Clinic) to predict the probability of malignancy of SPN with a diameter ranging between 4 and $30 \mathrm{~mm}$. Three clinical (age, smoking and history cancer) and radiological (diameter, spiculation and upper location) characteristics are considered as predictor of malignancy (26). The Brock University model was validated on a cohort of high-risk participants undergoing low-dose CT screening for lung cancer and performing this model calculator in low-risk patients would lead to an overestimation of the risk of malignancy. Thorough the evaluation of different parameter (age, sex, family history of lung cancer, emphysema nodule size and type, location and border characteristics) this model calculates the probability of malignancy. On the other hand, the Mayo Clinic is more reliable in predicting the risk of malignancy in SPNs discovered incidentally (9). Herder et al. performed an external validation of the Mayo Clinic by developing a model that predicts the risk of malignancy in SPNs using patient characteristics, nodule characteristics and the degree of absorption of FDG on PET-CT (27). Gould et al. developed another prediction malignancy model, Veterans Affair, which presented comparable accuracy to that of Mayo Clinic calculator, but considered only SPNs ranging in size from 7 to $30 \mathrm{~mm}$ in diameter and did not take into account the morphology of the nodule (28).

In addition, in 2014, the American College of Radiology (ACR) published the Lung-RADS Assessment Categories to standardize CT lung screening and management of results (29). Lung-RADS identifies five categories to differentiate high-risk from low-risk nodules using nodule type, nodule size, and growth:

* Category 0 (incomplete): previous CT not available for comparison or pulmonary parenchyma are not completely evaluated; in this case is necessary additional lung screening CT.

* Category 1 (negative): absence of nodules or nodules with clear benign characteristics; and is recommended continue annual LDCT screening (risk of malignancy $<1 \%$ ).

* Category 2 (benign appearance and low likelihood malignancy): this refers to perifissural nodules $<10 \mathrm{~mm}$; solid nodules $<6 \mathrm{~mm}$ or new $<4 \mathrm{~mm}$; part solid nodules $<6 \mathrm{~mm}$ in maximal diameter; nonsolid nodules (GGN) $<30 \mathrm{~mm}$; and annual LDCT screening (risk of malignancy $<1 \%$ ).

- Category 3 (probably benign): is for solid nodules $\geq 6$ to $<8 \mathrm{~mm}$; part solid nodules $\geq 6 \mathrm{~mm}$ total diameter with solid component $<6 \mathrm{~mm}$; non-solid nodules $(\mathrm{GGN})>30 \mathrm{~mm}$; in this case there is a $1-2 \%$ chance of malignancy and LDCT every six months is recommended.

* Category 4A (suspicious): this refers to solid nodules $\geq 8$ to $<15 \mathrm{~mm}$ or growing $<8 \mathrm{~mm}$ or new 
Table 3 National Comprehensive Cancer Network (NCCN) 2018, pulmonary nodule management

\begin{tabular}{lcc}
\hline Nodule type & Size, $\mathrm{mm}$ & Recommendation \\
\hline Solid & $<6$ & Annual screening \\
& $6-8$ & One scan at 6 months \\
& $>8$ & One scan at 3 months, PET, tissue sampling for high risk \\
Part solid & $<6$ & Annual screening \\
& $\geq 6$ & Based on size of solid component \\
Ground glass & $<6$ & Annual screening \\
& $\geq 6$ & Annual screening \\
\hline
\end{tabular}

PET, positron emission tomography.

nodules 6 to $<8 \mathrm{~mm}$; Part solid nodules $\geq 6 \mathrm{~mm}$ with solid component $\geq 6$ to $<8 \mathrm{~mm}$ or with a new or growing solid component $<4 \mathrm{~mm}$; in this category there is a $5 \%$ to $15 \%$ risk of malignant process and the patient should be to perform a LDCT at 3 months or PET/CT if there is a solid component $>8 \mathrm{~mm}$.

* Category 4B (very suspicious): is for solid nodules $\geq 15 \mathrm{~mm}$ or new or growing solid nodules $\geq 8 \mathrm{~mm}$; part solid nodules with a solid component $\geq 8 \mathrm{~mm}$ or new or growing solid component $\geq 4 \mathrm{~mm}$; at this level advisable chest CT with or without contrast, PET/CT and/or tissue sampling.

* Category 4X (very suspicious): includes categories 3 and 4 with additional features that increase the risk of malignancy.

\section{Management of pulmonary nodule}

SPN management ideally should include an interprofessional approach, evaluating the characteristics of the nodule, the patient's risk factors and also the patient's preferences (4). There are several guidelines of scientific societies that have developed detailed recommendations and algorithms for the management and decision making of the pulmonary nodule, but at the same time allow flexibility in the choice of the diagnostic protocol to be used based on the individual characteristics of the patients.

If pulmonary nodule is found during lung cancer screening programs, National Comprehensive Cancer Network (NCCN) guidelines should be applied. In 2018 there was an update of the NCCN guidelines (Table 3). Instead, if the SPN was identified incidentally, the Fleischner Society guidelines, British Thoracic Society
(BTS) guidelines or American College of Chest Physician (ACCP) guidelines are more applicable (24).

The Fleischner society (revised and update in 2017), BTS (released in 2015) and ACCP revised and updated in 2013) are the most influential and updated guidelines for the diagnosis and management of incidentally identified pulmonary nodules $(2,14)$ and they provide an evidencebased approach to guide clinicians to diagnosis.

Although the guidelines of the Fleischner, BTS and ACCP are similar, there are some important differences in the management of SPNs. Fleischner's guidelines do not apply to people under the age of 35 , immunocompromised patients at risk of infections or patients with known primary tumor at risk for metastasis (14). In contrast BTS guidelines include all SPN detected in patients aged $>18$ years, and include also patients with previous or current malignancy (30). In addition the BTS guidelines incorporated the use of risk predictive models into the decision-making algorithm (Brock university and Herder) and gave greater emphasis to VDT. Furthermore, the ACCP proposes a follow-up for nodules with a minimum diameter of $4 \mathrm{~mm}$, Fleischner society 6 or $100 \mathrm{~mm}^{3}$ and BTS 5 or $80 \mathrm{~mm}^{3}$ (13). Also, these guidelines have separate recommendations regarding intervals and total duration of follow ups: for sub-solid nodules, Fleischner society advises a 5-year surveillance, BTS 4 years and ACCP 3 years.

The Fleischner society in an international medical society and their recommendations are widely accepted and adopted world-wide. In 2017, the Fleischner society revised the guidelines on pulmonary nodule management. The new guidelines should eliminate thousands of unnecessary follow-up CTs, in fact, the level of attention was raised which, in the previous guidelines, was the presence of pulmonary nodules $<4 \mathrm{~mm}$. The average risk of cancer in 
Table 4 Management recommendations for solitary solid nodules by Fleischner society and ACCP guidelines

\begin{tabular}{|c|c|c|}
\hline Solid nodules & Nodule size & $\begin{array}{l}\text { Management } \\
\text { recommendation }\end{array}$ \\
\hline \multicolumn{3}{|c|}{ Fleischner society } \\
\hline \multicolumn{3}{|c|}{ Low risk patients $(<5 \%)$} \\
\hline & $<6 \mathrm{~mm}$ & No follow up \\
\hline & $6-8 \mathrm{~mm}$ & $\begin{array}{l}\text { CT at } 6-12 \text { months, then } \\
\text { consider CT at } 18-24 \\
\text { months }\end{array}$ \\
\hline & $>8 \mathrm{~mm}$ & $\begin{array}{l}\text { Consider CT at } 3 \text { months, } \\
\text { PET/CT, or tissue sampling }\end{array}$ \\
\hline \multicolumn{3}{|c|}{ High risk patients (>5\%) } \\
\hline & $<6 \mathrm{~mm}$ & Optional CT at 12 months \\
\hline & $6-8 \mathrm{~mm}$ & $\begin{array}{l}\text { CT at } 6-12 \text { months, then } \mathrm{CT} \\
\text { at } 18-24 \text { months }\end{array}$ \\
\hline & $>8 \mathrm{~mm}$ & $\begin{array}{l}\text { Consider CT at } 3 \text { months, } \\
\text { PET/CT, or tissue sampling }\end{array}$ \\
\hline
\end{tabular}

\section{ACCP}

Pts with no risk factors (nodule size)

$$
\begin{array}{ll}
\leq 4 \mathrm{~mm} & \text { follow up optional } \\
>4 \mathrm{~mm} \leq 6 \mathrm{~mm} & \text { CT at } 12 \text { months } \\
>6 \mathrm{~mm} \leq 8 \mathrm{~mm} & \begin{array}{l}
\text { CT at } 6,12,18 \text { and } 24 \\
\text { months }
\end{array}
\end{array}
$$

Pts with risk factors (nodule size)

$$
\begin{array}{ll}
\leq 4 \mathrm{~mm} & \begin{array}{l}
\text { CT at } 12 \text { months and annual } \\
\text { CT surveillance }
\end{array} \\
>4 \mathrm{~mm} \leq 6 \mathrm{~mm} & \begin{array}{l}
\text { CT at } 6,12, \text { and then } \\
\text { between } 18 \text { and } 24 \text { months }
\end{array} \\
>6 \mathrm{~mm} \leq 8 \mathrm{~mm} & \begin{array}{l}
\text { CT at } 3,6,9,12, \\
24 \text { months }
\end{array}
\end{array}
$$

$>8 \mathrm{~mm} \leq 30 \mathrm{~mm}$ (divided into three groups based on risk of

\begin{tabular}{|c|c|c|}
\hline $\begin{array}{l}\text { Sub-solid } \\
\text { nodules }\end{array}$ & Nodule size & $\begin{array}{l}\text { Management } \\
\text { recommendation }\end{array}$ \\
\hline \multicolumn{3}{|c|}{ Fleischner society } \\
\hline \multirow[t]{2}{*}{ Part Solid } & $<6 \mathrm{~mm}$ & No follow-up \\
\hline & $\geq 6 \mathrm{~mm}$ & $\begin{array}{l}\text { CT at } 6-12 \text { months If } \\
\text { unchanged and solid } \\
\text { component remains }<6 \mathrm{~mm} \text {, } \\
\text { annual CT for } 5 \text { years }\end{array}$ \\
\hline \multirow[t]{2}{*}{ Ground Glass } & $<6 \mathrm{~mm}$ & No follow-up \\
\hline & $\geq 6 \mathrm{~mm}$ & $\begin{array}{l}\text { CT at } 6-12 \text { months. } \\
\text { Consider CT every } 2 \text { years } \\
\text { until } 5 \text { years }\end{array}$ \\
\hline \multicolumn{3}{|l|}{ ACCP } \\
\hline \multirow[t]{2}{*}{ Part Solid } & $\leq 8 \mathrm{~mm}$ & CT at 3,12 and 24 months \\
\hline & $>8 \mathrm{~mm}$ & $\begin{array}{l}\text { CT with optional PET/CT, } \\
\text { biopsy/or surgical resection }\end{array}$ \\
\hline \multirow[t]{2}{*}{ Ground Glass } & $\leq 5 \mathrm{~mm}$ & No follow-up \\
\hline & $>5 \mathrm{~mm}$ & $\begin{array}{l}\text { Annual CT for at least } 3 \\
\text { years }\end{array}$ \\
\hline
\end{tabular}
malignancy)

Low (<5\%):CT at 3 to 6 months, 9 to 12 months and 18 to 24 months

Low/moderate (5-65\%): PET/CT and optional biopsy/resection

High (65\%): staging for surgical treatment

ACCP, American College of Chest Physicians; CT, tomography; $\mathrm{PET}$, positron emission tomography.
Table 5 Management recommendations for solitary sub-solid nodules by Fleischner society and ACCP guidelines

ACCP, American College of Chest Physicians; CT, tomography; PET, positron emission tomography.

nodules $<6 \mathrm{~mm}$ was estimated to be less than $1 \%$ in heavy smokers and less than $0.15 \%$ in non-smokers. Also, CT scan itself can rarely cause cancer. In high-risk patients with a solid SPN $<6 \mathrm{~mm}$, a follow-up CT is optional, while in low-risk individuals neither follow-up is necessary. If the SPN is stable for 2 years then it can be considered benign, while sub-solid nodules should be followed for at least 5 years because they may represent slower growing malignant process (13). Some studies have shown that the volume of the pulmonary nodule represents a more reliable and reproducible parameter than measurement of diameter, therefore in the latest guidelines the volume has been included as an option for monitoring the size and growth of the SPN (29).

Nodules between 6 and $8 \mathrm{~mm}$ require CT scan surveillance based on size nodule and the patient's risk factors. SPN $>8 \mathrm{~mm}$ with growth requires follow-up imaging at shorter time intervals, consider repeating CT at 3 months versus PET/CT scan or histological evaluation.

A summary of the scientific society recommendations for follow-up and management of SPN are reported in Tables 4,5. 
The pulmonary nodule that demonstrates clear dimensional growth on serial follow-up CT scan have a high probability of malignancy and biopsy or surgical resection should be guaranteed. The main options to perform tissue sampling are CT-guided transthoracic lung biopsy and bronchoscopy. The optimal technique to use depends on the location of the SPN, size nodule and also patient's comorbidities (24). Surgical resection options include open thoracotomy, video-assisted thoracic surgery (VATS) or robotic-assisted thoracic surgery (RATS). Patients with stage I Non-small cell lung cancer who cannot undergo surgery can be treated with the stereotactic body radiotherapy (SBRT); in patients undergoing SBRT the 5 -year survival is $37 \%$ versus $68 \%$ of the patients who received a lobectomy (4).

Despite continued technological advances in modalities such as CT, PET/CT, biopsy, and the development of increasingly accurate algorithms by scientific societies, the management of SPN remains a challenge. The complexity in the management of the SPNs is also explained by the low rate of compliance, by clinicians, to the recommendations proposed by the guidelines. CT scansion represent an important starting point in the pulmonary nodule evaluation process. Recent advances in CT technology make it possible to better characterize the lung lesion morphology and to establish a possible relationship between CT features and lung cancer subtypes (31). Lederlin et al. (32) reported that lepidic adenocarcinoma arises predominantly in the periphery and shows solidity/ground glass opacity pattern and bronchogram. Other authors suggested the existence of a possible association between molecular alterations (e.g., EGFR-ALK) and CT scan imaging (33): EGFR-mutated adenocarcinoma was significantly associated with a greater ground glass component while solid pulmonary nodule with lobulated margins and hypoattenuation at contrast-enhanced CT appears to be more related to ALK-rearrangement.

\section{Conclusions}

SPN is a common finding in clinical practice and its evaluation and management is a challenge for clinicians. The assessment of SPN should be started determining the pretest probability of malignancy; the goal is to identify and to treat early-stage lung cancers (34). Patient's characteristic, specific risk factors and radiological features give in information about pretest probability. In addition, there are validated prediction models for malignancy risk stratification that can help in the pulmonary nodule evaluation.

Pulmonary nodules are often benign, however in some cases they represent an early lung cancer, and high-risk patients are more likely to develop malignancy. In this context, screening programs with the aim of identifying pulmonary nodules at an early stage may be indicated.

The National Lung Screening Trial (NLST) was the first study to show that LDCT in high-risk individuals results in a $20 \%$ reduction in lung cancer mortality (35). Several randomized studies were conducted (MILD, ITALUNG, DANTE, LUSI, NELSON) comparing an annual screening strategy using LDCT versus "usual care". Recently the NELSON randomized study showed the benefit of periodic screening with LDCT with a reduction in mortality at 10 years of $24 \%$ in men and $33 \%$ in women. In recent years, some scientific societies have also published specific recommendations to support lung cancer screening programs.

The value of the LDCT lung cancer screening is widely accepted and several studies have demonstrated that may be effective in reducing lung cancer mortality, but there are still considerable uncertainties preventing its full spread (36). The main limitations concern cost-benefit effectiveness, overdiagnosis and radiation exposure. Continuing technological advances, especially radiological (e.g., artificial intelligence and deep learning) and histopathological advances (liquid biopsies), are likely to increase the efficacy of screening (37).

SPN requires an integrated and structured approach in order to detect early lung cancer and to avoid health damaging over investigations. Moreover, LDCT screening would be useful in high-risk individuals. Furthermore, it is of the utmost importance to sensitize the patient about the potential risks and benefits that could arise from the different management methods. Future directions of research should also include the development of simpler diagnostic algorithms so that they can be used by the entire scientific community.

\section{Acknowledgments}

Funding: None.

\section{Footnote}

Provenance and Peer Review: This article was commissioned by the Guest Editors (Duilio Divisi and Roberto Crisci) for the series "Solitary Pulmonary Nodule" published in $A M E$ Surgical fournal. The article has undergone external peer 
review.

Reporting Checklist: The authors have completed the Narrative Review reporting checklist. Available at https:// asj.amegroups.com/article/view/10.21037/asj-21-18/rc

Conflicts of Interest: All authors have completed the ICMJE uniform disclosure form (available at https://asj.amegroups. com/article/view/10.21037/asj-21-18/coif). The series "Solitary Pulmonary Nodule" was commissioned by the editorial office without any funding or sponsorship. The authors have no other conflicts of interest to declare.

Ethical Statement: The authors are accountable for all aspects of the work in ensuring that questions related to the accuracy or integrity of any part of the work are appropriately investigated and resolved.

Open Access Statement: This is an Open Access article distributed in accordance with the Creative Commons Attribution-NonCommercial-NoDerivs 4.0 International License (CC BY-NC-ND 4.0), which permits the noncommercial replication and distribution of the article with the strict proviso that no changes or edits are made and the original work is properly cited (including links to both the formal publication through the relevant DOI and the license). See: https://creativecommons.org/licenses/by-nc-nd/4.0/.

\section{References}

1. McNulty W, Baldwin D. Management of pulmonary nodules. BJR Open 2019;1:20180051.

2. Callister ME, Baldwin DR, Akram AR, et al. British Thoracic Society guidelines for the investigation and management of pulmonary nodules. Thorax 2015;70 Suppl 2:ii1-ii54.

3. Wahidi MM, Govert JA, Goudar RK, et al. Evidence for the treatment of patients with pulmonary nodules: when is it lung cancer?: ACCP evidence-based clinical practice guidelines (2nd edition). Chest 2007;132:94S-107S.

4. Wyker A, Henderson WW. Solitary Pulmonary Nodule. 2021. Available online: https://www.ncbi.nlm.nih.gov/ books/NBK556143/

5. Lazarus DR, Ost DE. The solitary pulmonary noduledeciding when to act? Semin Respir Crit Care Med 2013;34:748-61.

6. McWilliams A, Tammemagi MC, Mayo JR, et al. Probability of cancer in pulmonary nodules detected on first screening CT. N Engl J Med 2013;369:910-9.

7. Bourke W, Milstein D, Giura R, et al. Lung cancer in young adults. Chest 1992;102:1723-9.

8. Chan EY, Gaur P, Ge Y, et al. Management of the Solitary Pulmonary Nodule. Arch Pathol Lab Med 2017;141:927-31.

9. Khan T, Usman Y, Abdo T, et al. Diagnosis and management of peripheral lung nodule. Ann Transl Med 2019;7:348.

10. Patel VK, Naik SK, Naidich DP, et al. A practical algorithmic approach to the diagnosis and management of solitary pulmonary nodules: part 1: radiologic characteristics and imaging modalities. Chest 2013;143:825-39.

11. Peto R, Lopez AD, Boreham J, et al. Mortality from tobacco in developed countries: indirect estimation from national vital statistics. Lancet 1992;339:1268-78.

12. Mery CM, Pappas AN, Bueno R, et al. Relationship between a history of antecedent cancer and the probability of malignancy for a solitary pulmonary nodule. Chest 2004;125:2175-81.

13. Cruickshank A, Stieler G, Ameer F. Evaluation of the solitary pulmonary nodule. Intern Med J 2019;49:306-15.

14. MacMahon H, Naidich DP, Goo JM, et al. Guidelines for Management of Incidental Pulmonary Nodules Detected on CT Images: From the Fleischner Society 2017. Radiology 2017;284:228-43.

15. Karabulut N, Törü M, Gelebek V, et al. Comparison of low-dose and standard-dose helical CT in the evaluation of pulmonary nodules. Eur Radiol 2002;12:2764-9.

16. Mehta HJ, Ravenel JG, Shaftman SR, et al. The utility of nodule volume in the context of malignancy prediction for small pulmonary nodules. Chest 2014;145:464-72.

17. Gould MK, Fletcher J, Iannettoni MD, et al. Evaluation of patients with pulmonary nodules: when is it lung cancer?: ACCP evidence-based clinical practice guidelines (2nd edition). Chest 2007;132:108S-30S.

18. Nietert PJ, Ravenel JG, Leue WM, et al. Imprecision in automated volume measurements of pulmonary nodules and its effect on the level of uncertainty in volume doubling time estimation. Chest 2009;135:1580-7.

19. Xu DM, Gietema H, de Koning H, et al. Nodule management protocol of the NELSON randomised lung cancer screening trial. Lung Cancer 2006;54:177-84.

20. Soubani AO. The evaluation and management of the solitary pulmonary nodule. Postgrad Med J 2008;84:459-66.

21. Choromańska A, Macura KJ. Evaluation of solitary pulmonary nodule detected during computed tomography 
examination. Pol J Radiol 2012;77:22-34.

22. Bongiolatti S, Corzani R, Borgianni S, et al. Long-term results after surgical treatment of the dominant lung adenocarcinoma associated with ground-glass opacities. J Thorac Dis 2018;10:4838-48.

23. Khan AN, Al-Jahdali HH, Allen CM, et al. The calcified lung nodule: What does it mean? Ann Thorac Med 2010;5:67-79.

24. Nasim F, Ost DE. Management of the solitary pulmonary nodule. Curr Opin Pulm Med 2019;25:344-53.

25. Groheux D, Quere G, Blanc E, et al. FDG PET-CT for solitary pulmonary nodule and lung cancer: Literature review. Diagn Interv Imaging 2016;97:1003-17.

26. Swensen SJ, Silverstein MD, Ilstrup DM, et al. The probability of malignancy in solitary pulmonary nodules. Application to small radiologically indeterminate nodules. Arch Intern Med 1997;157:849-55.

27. Herder GJ, van Tinteren H, Golding RP, et al. Clinical prediction model to characterize pulmonary nodules: validation and added value of $18 \mathrm{~F}$-fluorodeoxyglucose positron emission tomography. Chest 2005;128:2490-6.

28. Gould MK, Ananth L, Barnett PG, et al. A clinical model to estimate the pretest probability of lung cancer in patients with solitary pulmonary nodules. Chest 2007;131:383-8.

29. van Riel SJ, Jacobs C, Scholten ET, et al. Observer variability for Lung-RADS categorisation of lung cancer screening CTs: impact on patient management. Eur Radiol 2019;29:924-31.

doi: $10.21037 /$ asj-21-18

Cite this article as: Gonfiotti A, Salvicchi A, Voltolini L. Narrative review of classification and management of solitary pulmonary nodule: the state of art. AME Surg J 2022;2:13.
30. Hein PA, Romano VC, Rogalla P, et al. Linear and volume measurements of pulmonary nodules at different CT dose levels - intrascan and interscan analysis. Rofo 2009;181:24-31.

31. Loverdos K, Fotiadis A, Kontogianni C, et al. Lung nodules: A comprehensive review on current approach and management. Ann Thorac Med 2019;14:226-38.

32. Lederlin M, Puderbach M, Muley T, et al. Correlation of radio- and histomorphological pattern of pulmonary adenocarcinoma. Eur Respir J 2013;41:943-51.

33. Hong SJ, Kim TJ, Choi YW, et al. Radiogenomic correlation in lung adenocarcinoma with epidermal growth factor receptor mutations: Imaging features and histological subtypes. Eur Radiol 2016;26:3660-8.

34. Gonfiotti A, Davini F, Vaggelli L, et al. Thoracoscopic localization techniques for patients with solitary pulmonary nodule: hookwire versus radio-guided surgery. Eur J Cardiothorac Surg 2007;32:843-7.

35. National Lung Screening Trial Research Team; Aberle DR, Adams AM, et al. Reduced lung-cancer mortality with low-dose computed tomographic screening. N Engl J Med 2011;365:395-409.

36. Snowsill T, Yang H, Griffin E, et al. Low-dose computed tomography for lung cancer screening in high-risk populations: a systematic review and economic evaluation. Health Technol Assess 2018;22:1-276.

37. Novellis P, Cominesi SR, Rossetti F, et al. Lung cancer screening: who pays? Who receives? The European perspectives. Transl Lung Cancer Res 2021;10:2395-406. 